\title{
PENERAPAN TEKNIK TOTAL TASK PRESENTATION UNTUK MENINGKATKAN KETERAMPILAN BUANG AIR KECIL PADA ANAK DENGAN DISABILITAS INTELEKTUAL MODERAT
}

\author{
Aryani Rahmah Utami, Mayke S. Tedjasaputra \\ Fakultas Psikologi Universitas Indonesia \\ Kampus Baru UI, Depok, Jawa Barat, Indonesia 16424 \\ aryanirahmahutami@gmail.com
}

\begin{abstract}
Children with intellectual disability (ID) have deficit in their adaptive functions, such as self-care in practical domain. The skill of self-care in moderate ID children can develop after being trained, although it takes a long time. One of skills that can be developed is urination skill. Urination skill is important to teach on children with ID so they can maintain their genital organs health independently. Therefore, interventions related to urination skill using behavior modification program with total task presentation technique are required. The purpose of this research is to evaluate the effectiveness of total task presentation technique to increase urination skill on child with moderate ID. This study used a single case subject A-B design that used to find changes in scores by comparing behavior observation data of participant's urination skill and make a data analysis. Participant in this study was a 10 years old boy who has deficit in urination skill. After the implementation of the intervention program in 16 sessions for 14 days with 81 trials, it was found that the total task presentation technique is effective to improve urination skill on a child with moderate ID. The participants has been able to take control the entire range of urinating behavior (22 chain of behaviors) independently. Previously, the child could only controlled the nine chain of behaviors independently.
\end{abstract}

Keywords: moderate level of intellectual disability; urinating skill; total task presentation

\begin{abstract}
Abstrak
Anak dengan disabilitas intelektual memiliki keterbatasan pada fungsi adaptifnya, salah satunya kemampuan bina diri yang terdapat dalam domain praktikal. Anak dengan disabilitas intelektual yang berada pada level moderat (moderate) mampu dilatih untuk dapat menguasai kemampuan bina dirinya, meskipun membutuhkan waktu yang lama untuk mengajarkan. Salah satu kemampuan bina diri yang dapat dilatih adalah keterampilan buang air kecil (BAK). Keterampilan BAK penting untuk diajarkan pada anak dengan disabilitas intelektual agar mereka dapat menjaga kebersihan organ genitalnya secara mandiri. Oleh karena itu, perlu dilakukan intervensi terkait keterampilan BAK menggunakan program modifikasi perilaku dengan teknik total task presentation. Penelitian ini bertujuan untuk menguji efektivitas penerapan total task presentation untuk meningkatkan keterampilan BAK pada anak dengan disabilitas intelektual moderat. Metode dalam penelitian ini menggunakan single case subject $A-B$ design dengan menggunakan alat tes observasi untuk mendapatkan hasil serta melakukan analisis data berdasarkan data yang diperoleh. Partisipan dalam penelitian berjumlah satu orang anak laki-laki berusia 10 tahun yang memiliki keterbatasan (perilaku defisit) dalam melakukan keterampilan BAK. Setelah penerapan teknik total task presentation selama 16 sesi dalam 14 hari dengan 81 percobaan didapatkan hasil bahwa teknik total task presentation efektif untuk meningkatkan keterampilan BAK pada anak dengan disabilitas intelektual moderat. Partisipan berhasil menguasai seluruh rangkaian perilaku BAK (22 chain of behaviors) secara mandiri dari yang sebelumnya hanya menguasai sembilan rangkaian perilaku secara mandiri.
\end{abstract}

Kata kunci: disabilitas intelektual moderat; keterampilan buang air kecil; total task presentation 


\section{PENDAHULUAN}

Disabilitas intelektual merupakan suatu gangguan yang ditandai oleh keterbatasan yang signifikan pada fungsi mental (seperti daya nalar, pemecahan masalah, dan kemampuan belajar) maupun fungsi adaptif yang mencakup kemampuan konseptual, sosial, dan praktikal dalam kehidupan sehari-hari (Nelson \& Israel, 2015). Dalam Diagnostic and Statistical Manual of Mental Disorder edisi kelima (DSM V) membagi disabilitas intelektual berdasarkan tingkat keparahan dalam fungsi kemampuan adaptif yang berkisar pada tingkatan ringan (mild) hingga sangat berat (profound). Pada masing-masing tingkat memiliki batasan kemampuan anak dalam melakukan sesuatu, sebagai contoh berkaitan dengan bina diri, individu dapat menunjukkan kemampuan yang sesuai dengan usianya namun tetap membutuhkan dukungan dalam melakukan tugas yang kompleks (mild), membutuhkan pengajaran dan waktu yang lebih lama untuk mencapai kemandirian saat masa dewasa (moderate), membutuhkan bantuan dalam melakukan seluruh aktivitas (severe), atau bergantung kepada orang lain untuk seluruh aspek perawatan diri (profound). Jenis bantuan dan pendampingan yang dibutuhkan anak dengan disabilitas intelektual tergantung dari kemampuan kognitif dan ekspektasi yang diberikan lingkungan terhadap mereka (Behrani \& Deka, 2016). Individu dengan disabilitas intelektual ringan (mild) dan moderat dapat secara mandiri mengurus dan merawat kebutuhan sehari-hari jika diberikan kesempatan untuk mempelajari dan mempraktikannya. Salah satu keterampilan bina diri yang dapat diajarkan adalah keterampilan buang air kecil (BAK).

Keterampilan BAK merupakan bagian dari toileting skill yang harus dikuasai oleh setiap orang, sebab apabila terhambat, dapat membuat terganggunya seluruh kualitas hidup individu, baik individu yang memiliki gangguan perkembangan maupun tidak (Rinald \& Mirenda, 2012). Selain itu, pada anak, kemampuan toileting perlu dilatih dalam rangka menjaga kesehatan genital (Greer, 2013), dapat melakukan secara tepat (Emerson, Hatton, Dickson, Caine, \& Bromley, 2012), dan menghindari anak dengan kemungkinan mengalami pelecehan seksual (Greer, 2013).

Sesuai tahap perkembangan manusia, anak pada umumnya sudah mampu mengatur kegiatan toileting-nya sejak usia 9-10 tahun secara mandiri dan tanpa harus diingatkan oleh pengasuhnya (Marotz \& Ellen, 2013). Berbeda halnya dengan anak dengan disabilitas intelektual, mereka seringkali mengalami hambatan dalam kemampuan toileting, terutama pada anak yang memiliki tingkat disabilitas intelektual yang parah (minimal berada di level moderat) (Levato dkk., 2016). Hal tersebut terjadi karena terbatasnya kemampuan kognitif atau kesulitan komunikasi yang dialami anak dengan disabilitas intelektual.

Dalam DSM V, keterampilan BAK merupakan kemampuan yang dikategorikan sebagai bagian dari merawat kebersihan diri pada aspek praktikal. Anak dengan kondisi disabilitas intelektual moderat dinilai masih mampu untuk melakukan BAK secara mandiri, namun membutuhkan waktu yang lama untuk dilatih dan memerlukan dukungan orang lain untuk dapat melakukannya dengan benar (American Psychiatric Association, 2013). Oleh karena itu, anak dengan kondisi disabilitas intelektual moderat membutuhkan intervensi untuk dapat meningkatkan keterampilan BAK yang disupervisi secara penuh.

Intervensi yang dapat diberikan harus menyesuaikan dengan karakteristik dari disabilitas intelektual moderat. Syarat untuk memberikan intervensi pada anak disabilitas intelektual moderat adalah menggunakan kalimat-kalimat sederhana serta arahan yang jelas, melibatkan caregiver utama sebagai pendamping anak, dan memiliki media untuk mempertahankan perilaku (Collins, 2012). 
Intervensi yang memenuhi syarat tersebut adalah program modifikasi perilaku (behavior modification) yang memiliki teknik dan media arahan yang beragam yang dapat disesuaikan dengan kondisi anak, berbasis reinforcermentbased on behavior, dan dalam pelaksanaan program dapat melibatkan orangtua atau pengasuh utama lainnya.

Penelitian yang menguji efektivitas suatu program intervensi terhadap pembentukan keterampilan bina diri pada anak-anak yang memiliki keterbatasan kognitif di Indonesia sudah banyak dilakukan. Hanya saja, penelitian yang secara spesifik menguji pembentukan keterampilan BAK pada anak dengan disabilitas intelektual moderat masih sulit ditemukan. Penelitian mengenai pembentukan keterampilan bina diri menggunakan prinsip-prinsip dari program modifikasi perilaku yang menerapkan metode yang berbeda-beda, seperti penerapan metode total task presentation untuk membentuk perilaku menggosok gigi pada anak dengan disabilitas intelektual moderat yang dilakukan oleh Kusharyani dan Kurnianingrum (2017) dan penerapan metode prompting dan positive reinforcement untuk membentuk perilaku mengancingkan baju pada anak dengan disabilitas intelektual moderat yang dilakukan oleh Murpratiwi dan Tjakrawilaksana (2017). Hasil yang didapatkan dari penelitian tersebut menunjukan adanya efektivitas dari intervensi yang diterapkan dan terbukti dapat melatih anak dengan disabilitas intelektual moderat menjadi lebih mandiri dalam merawat diri.

Penelitian mengenai BAK pada anak dengan disabilitas intelektual lebih banyak dilakukan di luar negeri. Seperti penelitian yang dilakukan oleh Rinald dan Mirenda (2012), Kroeger dan Sorensen-Burnworth (2009) serta Doan dan Toussaint (2016) yang menggunakan metode rapid toilet training (RTT) untuk melatih keterampilan toileting pada anak dengan disabilitas intelektual. Metode tersebut memiliki beberapa kesamaan dengan program modifikasi perilaku, yaitu bagian dari terapi perilaku, menggunakan reward atau punishment untuk memperkuat perilaku, dan melibatkan orangtua sebagai partisipan. Fokus metode RTT adalah mengupayakan agar anak tidak mengompol dan berinisiatif pergi ke kamar mandi ketika merasakan hasrat untuk BAK. Akan tetapi, metode RTT ini tidak memiliki sesi untuk mengajarkan anak dalam melakukan BAK dengan urutan perilaku BAK yang sesuai. Metode RTT berfokus agar anak disiplin untuk pergi ke toilet dan duduk di kloset ketika BAK. Jika metode RTT diberikan pada anak disabilitas intelektual moderat, dinilai kurang memberikan dampak yang sesuai karena kebutuhan anak disabilitas intelektual moderat tidak hanya sampai pada duduk di kloset, tetapi juga butuh mempelajari BAK dengan tahap perilaku yang benar hingga ia dapat membasuh dan memakai celana kembali. Oleh karena itu, metode RTT dirasa kurang sesuai. Berbeda dengan program modifikasi perilaku yang salah satu tekniknya menguraikan urutan dalam melakukan BAK secara terperinci. Semakin konkret dan jelas tahap yang harus dilakukan oleh anak, maka semakin mudah anak disabilitas intelektual moderat memahami keterampilan tersebut (Deshmukh, 2016). Dapat disimpulkan program modifikasi perilaku lebih sesuai untuk diberikan kepada anak disabilitas intelektual moderat.

Program modifikasi perilaku adalah intervensi yang berlandaskan pada pendekatan behavioristik yang dirancang untuk meningkatkan perilaku adaptif dan mengurangi perilaku maladaptif yang berlebihan dalam kehidupan sehari-hari (Lakhan, 2014). Program ini memiliki banyak teknik yang dapat diterapkan, salah satunya adalah teknik total task presentation yang terdapat dalam metode chaining. Teknik total task presentation dipilih karena dinilai dapat berdampak efektif ketika diterapkan pada anak yang memiliki keterbatasan kognitif. Hasil penelitian menunjukan bahwa dengan menggunakan teknik total-task presentation, individu dengan keterbatasan intelektual dapat lebih cepat 
menguasai perilaku yang disasar (Lakhan, 2014). Teknik tersebut membantu individu untuk mengoptimalkan kemandiriannya di setiap percobaan, terutama bagi individu yang sudah mulai mengenal beberapa langkah yang dibutuhkan untuk menyelesaikan rangkaian perilaku (behavioral chain) yang disasar. Oleh karena itu, tujuan penelitian ini adalah untuk menguji efektivitas penerapan teknik total task presentation untuk meningkatkan keterampilan BAK pada anak dengan disabilitas intelektual moderat. Hipotesis dari penelitian ini adalah penerapan program modifikasi perilaku dengan teknik total task presentation dapat meningkatkan keterampilan BAK pada anak dengan disabilitas intelektual moderat.

\section{METODE}

Desain penelitian yang digunakan dalam penelitian ini adalah single-subject design, atau disebut juga dengan single-case design. Desain dengan single-subject merupakan sebuah penelitian yang menggunakan satu partisipan untuk menetapkan adanya hubungan sebabakibat (Gravetter \& Forzano, 2012). Singlesubject design dipilih karena cenderung lebih fleksibel dan berkembang sesuai dengan kondisi serta respon yang diberikan oleh partisipan serta tidak membutuhkan adanya standarisasi kondisi perlakuan pada partisipan yang berbeda (Gravetter \& Forzano, 2012). Lebih lanjut, sebagai penelitian kuasi eksperimen maka dalam penelitian ini dilakukan pengamatan dan perbandingan perilaku partisipan sebelum dan sesudah pemberian intervensi (perlakuan).

Partisipan dalam penelitian ini hanya satu orang yaitu anak laki-laki berinisial $\mathrm{Y}$ berusia 10 tahun 2 bulan yang didiagnosis mengalami disabilitas intelektual level moderat. Y merupakan anak ke-2 dari 4 bersaudara yang tinggal di Depok dan bersekolah di sekolah luar biasa swasta depok. Hasil pemeriksaan psikologis menunjukan bahwa seluruh aspek perkembangannya berada jauh di bawah ratarata anak seusianya (10 tahun). Y mampu memahami perkataan orang lain dan merespon pembicaran orang lain ketika diberikan suatu perintah sederhana. Hanya saja, respon $\mathrm{Y}$ terbatas pada bahasa tubuh, tanpa disertai katakata yang bermakna. Ketika dilatih oleh orangtua untuk mengerjakan suatu keterampilan, Y membutuhkan waktu yang lama untuk mempelajari hal baru, perlu dijelaskan dan diingatkan berulang kali, serta diberikan contoh konkret. Perkembangan motorik kasar Y saat ini tidak mengalami masalah. Y sudah mampu berjalan, berlari, melompat dengan tepat, dan menyeimbangkan tubuhnya dengan baik. Akan tetapi, ketika melakukan aktivitas, Y belum mampu mengontrol tenaga yang harus dikeluarkan. Pada kemampuan praktikal sederhana, Y belum sepenuhnya mampu melakukan aktivitas bantu diri, walaupun ada beberapa kegiatan bantu diri yang sudah mampu Y lakukan, seperti melepas dan memakai kaos dan celana berkaret, serta makan minum dengan alat makan. Selain kegiatan tersebut, Y belum dapat melakukan dengan benar dan masih membutuhkan bantuan, seperti BAK dan buang air besar (BAB), mandi, mengeringkan badan, serta melepas dan memakai pakaian berkancing. Berdasarkan paparan kondisi tersebut di atas, nampak bahwa Y masih membutuhkan supervisi secara penuh dari orangtua untuk melakukan keterampilan merawat diri sederhana.

Metode pengambilan data dilakukan dengan cara direct. Direct assessment dilakukan melalui observasi dan mencatat perilaku BAK. Metode pencatatan kemunculan perilaku menggunakan interval recording. Metode ini dipilih untuk melihat kemunculan perilaku $\mathrm{Y}$ dalam melakukan rangkaian kegiatan yang diinstruksikan selama 3 jam yang dibagi setiap 30 menit sekali. Selama program dijalankan, observer mencatat keberhasilan $\mathrm{Y}$ di setiap percobaannya untuk melihat keberhasilan kegiatan di setiap sesi program, dan perkembangan keberhasilan Y selama program dilaksanakan. Peneliti merangkap menjadi observer serta pemberi intervensi dan dilakukan hanya seorang diri. Hal tersebut dilakukan 
karena keterbatasan volume ruangan ketika berada di kamar mandi. Jika lebih dari dua orang, maka cukup mengganggu gerak dan aktivitas yang akan dilakukan.

Metode analisis data yang digunakan pada penelitian single case dilakukan melalui analisis visual dengan membandingkan data hasil asesmen awal dan akhir yang disajikan dalam bentuk grafik (Gravetter dan Forzano, 2012). Dalam penelitian ini variabel yang akan diukur adalah perilaku BAK dengan melihat kemampuan partisipan untuk melakukan BAK sesuai urutan kegiatan dalam task analysis.

Intervensi ini diawali dengan meminta persetujuan orangtua untuk mengikuti penelitian; screening dan pengukuran baseline perilaku BAK pada partisipan; dilanjutkan dengan pelaksanaan intervensi; dan melakukan follow up. Formulir persetujuan dan informasi terkait penelitian telah dibaca, dibahas, dan ditandatangani oleh orangtua sebelum tahap intervensi dilakukan. Tahap screening dilakukan untuk memperoleh gambaran perilaku dari Y. Pada tahap ini juga dilakukan analisis fungsi perilaku/ functional behavioral assessment untuk dapat mengidentifikasi hubungan antara anteseden, perilaku, dan konsekuensi agar dapat membuat program modifikasi perilaku yang efektif (Kazdin, 2013). Setelah itu dilakukan pengukuran baseline untuk mengetahui kualitas kemampuan BAK dan menghitung frekuensi perilaku BAK yang ditampilkan oleh Y dalam satu waktu. Tahap pelaksanaan intervensi dimulai dengan melakukan rancangan program yang telah disusun menjadi 16 sesi. Terakhir adalah tahap follow up untuk melihat perubahan perilaku yang dicapai oleh Y. Follow up dilakukan sebanyak dua kali, yaitu satu minggu dan dua minggu setelah program selesai dilaksanakan.

Prosedur penelitian ini menerapkan intervensi berdasarkan program modifikasi perilaku yang menggunakan teknik total task presentation. Penggunaan total-task presentation diawali dengan melakukan task analysis atau mengurai perilaku besar menjadi urutan-urutan perilaku kecil (behavioural chain) berdasarkan teori yang disesuaikan dengan budaya individu. Setelah dilakukan task analysis, individu tersebut diajarkan untuk melakukan kegiatan sesuai urutan perilaku dari task analysis. Hal tersebut dilakukan secara terus menerus sehingga individu dapat menyelesaikan behavioural chain yang disasar secara mandiri. Dengan demikian, setiap langkah yang belum dikuasai oleh individu diajarkan secara bersamaan. Teknik total-task presentation digunakan untuk mengajarkan behavioural chain yang relatif sederhana dan individu yang disasar sudah (mulai) mampu menjalankan beberapa langkah perilaku yang dibutuhkan, namun masih perlu dilatih untuk menjalankannya secara runut dan konsisten.

Sebelum melakukan total task presetation diperlukan analisis serangkaian perilaku untuk mengidentifikasi perilaku sesuai dengan tahap urutannya berdasarkan stimulus (diescriminative stimulus/ SD) dan respon, atau biasa disebut sebagai task analysis. Task analysis dapat dilakukan dengan mencatat hasil observasi perilaku yang menjadi target atau mewawancarai significant other yang kompeten (Jameson, Walker, Utley, \& Maughan, 2012). Hal tersebut dilakukan untuk mendapatkan rangkaian perilaku sesuai tahap urutan berdasarkan stimulus (discriminative stimulus/ $S D$ ) dan respon. Menurut Wantah (2007), urutan dalam melakukan BAK di Indonesia adalah sebagai berikut:

1. Menyiapkan air, ember/bak air dan tissue.

2. Menutup pintu kamar mandi.

3. Membuka pakaian luar dan digantungkan di tempat yang telah disediakan atau di pintu kamar mandi.

4. Membuka pakaian dalam dan kemudian menghadap kloset.

5. Setelah selesai maka anak perlu membersihkan kelaminnya hingga bersih.

6. Memakai pakaian.

7. Membuka pintu toilet. 
Berdasarkan pendapat dari Wantah (2007), peneliti dapat menyesuaikan kembali dengan kebiasaan BAK yang dilakukan di rumah partisipan. Hasil wawancara dengan ibu dan observasi mengenai langkah BAK yang dilakukan di rumah, didapatkan hasil task analysis dari perilaku BAK di kamar mandi rumah yang diuraikan pada Tabel 1.

Tabel 1.

Hasil Task Analysis BAK

\begin{tabular}{|c|c|c|}
\hline No. & Discriminative Stimulus (SD) & Respon \\
\hline 1 & Ingin BAK. & Masuk ke kamar mandi. \\
\hline 2 & Berada di depan pintu dalam kamar mandi. & Menutup pintu kamar mandi. \\
\hline 3 & Berdiri membelakangi pintu. & Berjalan menuju ke depan kloset. \\
\hline 4 & Berada di depan kloset. & Membuka celana. \\
\hline 5 & Penis sudah dikeluarkan dari celana. & $\begin{array}{l}\text { Memegang penis dengan tangan kiri dan tangan } \\
\text { kanan menahan baju. }\end{array}$ \\
\hline 6 & Penis dipegang dan baju sudah ditahan. & Mengeluarkan urin ke dalam lubang kloset. \\
\hline 7 & Melepas tangan kanan dari menahan baju. & $\begin{array}{l}\text { Mengambil air dari ember menggunakan gayung } \\
\text { dengan tangan kanan. }\end{array}$ \\
\hline 8 & Menggenggam gayung di tangan kanan. & $\begin{array}{l}\text { Menyiram tangan kiri dengan air dari gayung yang } \\
\text { dipegang tangan kanan. }\end{array}$ \\
\hline 9 & Tangan kiri sudah basah. & Membasuh penis dengan tangan kiri. \\
\hline 10 & Menggenggam gayung di tangan kanan. & $\begin{array}{l}\text { Menyiram tangan kiri dengan air dari gayung yang } \\
\text { dipegang tangan kanan. }\end{array}$ \\
\hline 11 & Tangan kiri sudah basah. & Membasuh penis dengan tangan kiri. \\
\hline 12 & Menggenggam gayung di tangan kanan. & $\begin{array}{l}\text { Menyiram tangan kiri dengan air dari gayung yang } \\
\text { dipegang tangan kanan. }\end{array}$ \\
\hline 13 & Tangan kiri sudah basah. & Membasuh penis dengan tangan kiri. \\
\hline 14 & Selesai membasuh penis. & Meletakan gayung di ember \\
\hline 15 & Gayung sudah di ember. & Memakai celana. \\
\hline 16 & Celana sudah dipakai secara tepat. & $\begin{array}{l}\text { Mengambil air dari ember menggunakan gayung } \\
\text { dengan tangan kanan. }\end{array}$ \\
\hline 17 & Gayung di tangan kanan. & $\begin{array}{l}\text { Mencuci tangan kiri dengan cara menyiram tangan } \\
\text { kiri dengan air dari gayung yang dipegang tangan } \\
\text { kanan. Melakukannya di atas lobang kloset. }\end{array}$ \\
\hline 18 & Gayung di tangan kanan. & $\begin{array}{l}\text { Mengambil air dari ember menggunakan gayung } \\
\text { dengan tangan kanan. }\end{array}$ \\
\hline 19 & Gayung sudah berisi air. & Menyiram kloset dengan air dari gayung. \\
\hline 20 & Urin sudah tersiram. & Berjalan ke depan gantungan handuk tangan. \\
\hline 21 & Berada di depan handuk tangan. & Mengeringkan tangan dengan handuk tangan. \\
\hline 22 & Tangan sudah kering & Keluar dari kamar mandi \\
\hline
\end{tabular}

Catatan: Pada penelitian ini perbedaan dengan pendapat Wantah (2007) terletak pada tambahan kegiatan mencuci tangan setelah membasuh kelamin.

Teknik total-task presentation merupakan teknik yang menerapkan prosedur prompt dan fading secara sistematis pada setiap stimulusrespon yang terdapat pada rangkaian perilaku. Prompt yang diberikan adalah physical, gesture, dan verbal prompt. Penggunaan teknik-teknik prompt tersebut dilakukan dengan metode most- to-least prompting and fading, yaitu menggunakan jenis prompt dimulai dari prompt dengan tingkat intrusive tertinggi (full physical prompt), sampai prompt terendah (verbal prompt) dan jika belum menguasai diganti ke prompt tertinggi (kembali ke full physical prompt). Jika anak sudah mampu melakukan 
perilaku yang diharapkan tanpa adanya prompt, secara bertahap prompt pun dihilangkan (fading) (Sabielny \& Cannela-Malone, 2014). Pada intervensi ini, penggunaan gesture dan full physical prompt selalu diikuti dengan verbal prompt.

Pemberian prompt juga diiringi dengan reinforcer sebagai konsekuensi yang diterima anak setelah menampilkan perilaku yang diinginkan. Reinforcer menggunakan prinsip positive reinforcement. Positive reinforcement diberikan dalam bentuk social reinforcer dan consumable reinforcer saat anak berhasil menampilkan perilaku BAK. Social reinforcer digunakan karena mudah dilakukan dan dapat terus diterapkan meskipun program telah usai. Sementara itu, consumable reinforcer dipilih karena partisipan sangat suka makan, dan secara teknis penyediaan consumable dan social reinforcer mudah didapatkan. Social reinforcer diberikan secara langsung setelah perilaku yang diharapkan muncul (immediate). Consumable reinforcer diberikan secara tidak langsung atau ada jarak pemberian reinforcer setelah perilaku yang diharapkan muncul (intermittent). Pemberian consumable reinforcer diberikan di luar kamar mandi agar tidak membentuk kebiasaan baru pada partisipan untuk makan di dalam kamar mandi. Pemberian reinforcer yang akan digunakan adalah fixed ratio dengan memberikan reinforcement setelah satu perilaku berhasil ditampilkan oleh partisipan. Bentukbentuk positive reinforcement yang diberikan kepada partisipan disusun dari urutan yang paling disukai partisipan dapat dilihat pada Tabel 2.

Selain itu, peneliti juga melakukan setting event dengan memberikan minuman air mineral dan meletakan ember, gayung, serta handuk tangan di posisi yang dapat dijangkau oleh partisipan. Minuman diberikan selama penelitian agar partisipan merasa ingin BAK dengan cara memberikan air mineral setiap 30 menit sekali sebanyak maksimal $1 / 2$ gelas air mineral atau 120 ml. Pemberian air minum setiap 30 menit sekali merupakan bagian dari metode RTT dalam penelitian Kroeger dan Sorensen-Burnworth (2009) yang diadaptasi oleh peneliti agar merangsang partisipan untuk BAK. Pelaksanaan program intervensi dalam penelitian ini dilakukan di rumah partisipan selama 3 jam per hari.

Tabel 2. Urutan Reinforcer

\begin{tabular}{|c|c|c|}
\hline Urutan & $\begin{array}{l}\text { Inventori } \\
\text { kesukaan }\end{array}$ & $\begin{array}{l}\text { Bentuk positive } \\
\text { reinforcement }\end{array}$ \\
\hline 1 & Jelly Inaco & $\begin{array}{l}\text { Consumable } \\
\text { reinforcer }\end{array}$ \\
\hline 2 & Hello panda & $\begin{array}{l}\text { Consumable } \\
\text { reinforcer }\end{array}$ \\
\hline 3 & Permen Yupi & $\begin{array}{l}\text { Consumable } \\
\text { reinforcer }\end{array}$ \\
\hline 4 & $\begin{array}{l}\text { Permen Chaca } \\
\text { milk }\end{array}$ & $\begin{array}{l}\text { Consumable } \\
\text { reinforcer }\end{array}$ \\
\hline 5 & Biskuit Oreo mini & $\begin{array}{l}\text { Consumable } \\
\text { reinforcer }\end{array}$ \\
\hline 6 & Coklat Chic choc & $\begin{array}{l}\text { Consumable } \\
\text { reinforcer }\end{array}$ \\
\hline 7 & Marshmallow & $\begin{array}{l}\text { Consumable } \\
\text { reinforcer }\end{array}$ \\
\hline 8 & $\begin{array}{l}\text { Pujian ("betul", } \\
\text { "pintar", } \\
\text { hebat") }\end{array}$ & Social reinforcer \\
\hline
\end{tabular}

\section{HASIL DAN PEMBAHASAN}

Secara kesuluruhan, penelitian dilakukan selama 18 hari, yaitu 2 hari untuk pengukuran baseline, 14 hari pelaksanaan intervensi, dan 2 hari untuk follow up. Dari total percobaan yang dilakukan sebanyak 105 percobaan, yaitu 12 percobaan pada sesi baseline, 81 percobaan pada sesi intervensi, dan 12 percobaan pada sesi follow up.

Pada saat baseline, hasil identifikasi menunjukkan bahwa orangtua yang selalu membantu $\mathrm{Y}$ ketika $\mathrm{Y}$ ingin BAK membuat $\mathrm{Y}$ tidak terlatih untuk melakukan BAK dengan benar. Konsekuensinya Y menjadi tidak terlatih untuk melakukan BAK dengan benar dan mandiri. Berdasarkan perilaku dari task analysis (Tabel 1), Y secara konsisten menguasai 9 
perilaku selama 12 kali percobaan. Setelah dilakukan intervensi, Y mulai menunjukan perkembangan yang baik dengan bertambahnya penguasaan perilaku pada setiap percobaannya. Kemudian pada saats sesi follow up, secara konsisten juga menunjukan tetap bertahannya
22 perilaku yang dikuasai $\mathrm{Y}$ setelah mengikuti intervensi. Hasil penelitian yang didapatkan setelah melakukan baseline, pelaksanaan intervensi, dan follow up digambarkan dalam Gambar 1.

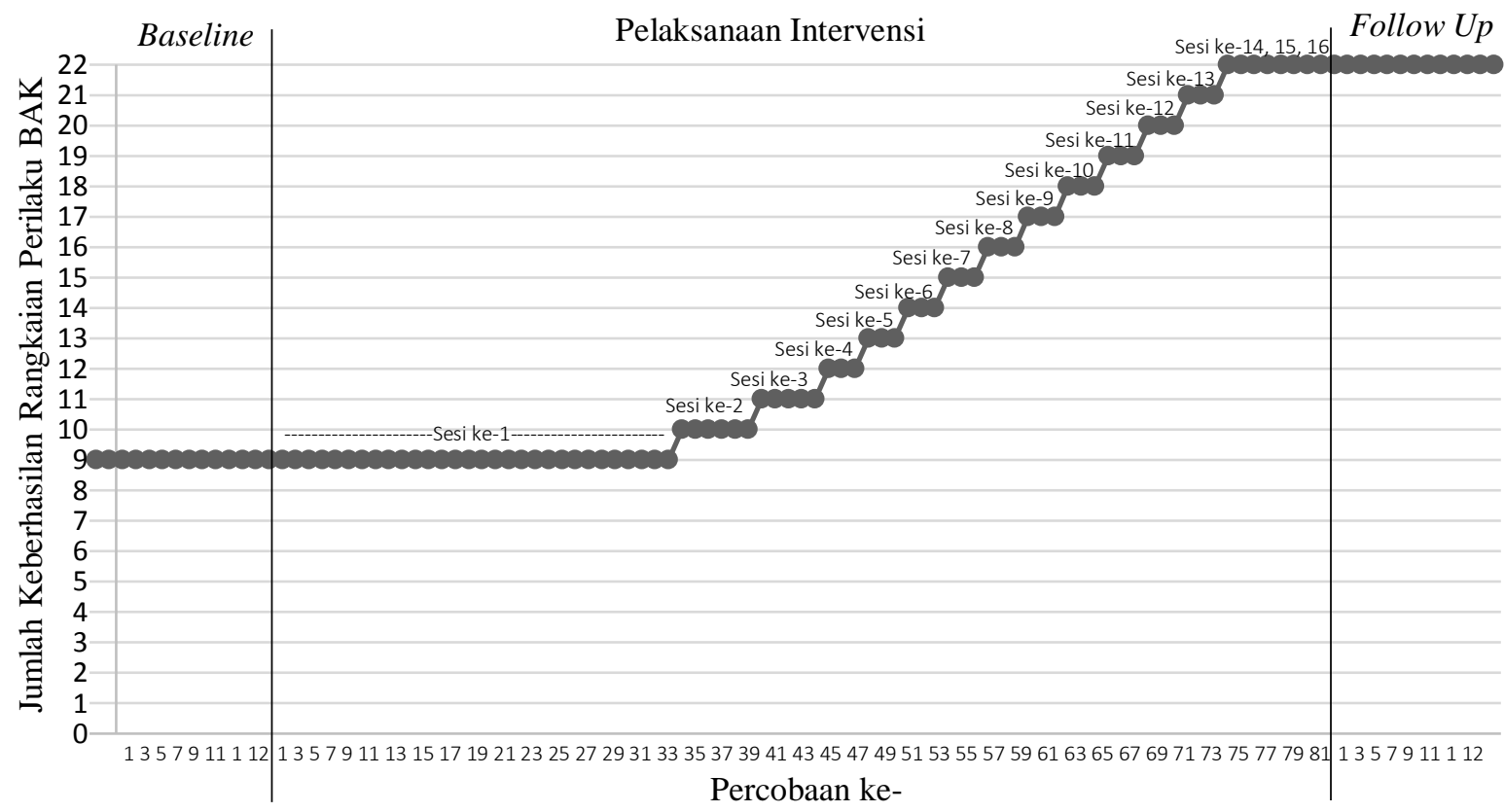

Catatan: Pada grafik, jumlah keberhasilan rangkaian perilaku BAK diukur berdasarkan pada Tabel 1 .

\section{Gambar 1. Penguasaan Rangkaian Perilaku BAK}

Dengan pemberian teknik total-task Percobaan ke-31 terletak pada sesi ke-2. presentation, keterampilan BAK Y meningkat. Artinya, partisipan mulai mengalami Dari 81 percobaan yang telah dilakukan pada sesi intervensi dapat disimpulkan bahwa terjadi peningkatan penguasaan perilaku BAK pada Y. Perbandingan data baseline dan follow up menunjukan adanya peningkatan, yaitu dari hanya menguasai 9 chain of behavior menjadi 22 chain of behavior (seluruh rangkaian perilaku) secara mandiri. Selain itu, pada Gambar 1 juga menunjukan bahwa kemampuan Y tetap bertahan bahkan pada sesi follow up. Hal tersebut menunjukan bahwa Y sudah mampu BAK secara mandiri dengan konsisten.

Peningkatan mulai terjadi pada percobaan ke-31 yang ditandai dengan bertambahnya penguasaan perilaku Y dari 9 menjadi 10 perilaku. perkembangan perilaku setelah melakukan percobaan selama 30 kali pada sesi ke-1. Setelah percobaan ke-31, partisipan terus mengalami peningkatan penguasaan perilaku hingga 16 sesi atau percobaan ke-81.

Hasil penelitian menunjukkan bahwa program modifikasi perilaku yang menggunakan teknik total-task presentation efektif dalam meningkatkan kemampuan BAK pada anak dengan disabilitas intelektual moderat berusia 10 tahun 2 bulan. Hasil tersebut sejalan dengan penelitian-penelitian sebelumnya yang menyatakan bahwa intervensi modifikasi perilaku sudah terbukti secara ilmiah efektif digunakan untuk meningkatkan keterampilan 
bantu diri pada anak dengan disabilitas intelektual (Obi dkk., 2011).

Terdapat beberapa faktor yang berkontribusi terhadap efektivitas program ini. Faktor pertama adalah penggunaan teknik total-task presentation. Menurut Jameson dkk. (2012), teknik tersebut efektif digunakan pada individu yang sudah mulai bisa melaksanakan beberapa rangkaian perilakunya dan sudah cukup familiar dengan rangkaian perilakunya, namun masih butuh mempelajari urutannya dengan lebih tepat. Pada Y, hasil baseline menunjukkan bahwa ia sudah familiar dan dapat melakukan beberapa chain of behaviors di perilaku BAK. Akan tetapi, ia belum bisa melakukan serangkaian perilaku BAK secara lengkap. Oleh karena itu, dengan bantuan teknik total-task presentation yang terfokus untuk mengajarkan perilaku yang berurutan dan berulang, membuatnya bisa mempelajari perilaku BAK dalam waktu yang relatif singkat.

Keberhasilan dari penerapan total-task presentation ditentukan juga oleh task analysis yang jelas (Miltenberger, 2012). Jameson dkk.a (2012) mengungkapkan bahwa task analysis menjadi suatu pedoman dalam melatih keterampilan anak. Perilaku-perilaku yang menjadi target pelatihan akan semakin mudah dicapai jika penguraian perilaku semakin konkret dan berurutan. Sebaliknya, jika task analysis yang dilakukan belum jelas dan ada perilaku yang ambigu, maka akan memengaruhi efektivitas dari total-task presentation. Setiap perilaku yang terdapat dalam task analysis dikatakan sudah terbentuk, apabila perilaku tersebut sudah dilakukan tanpa adanya bantuan dari orang dewasa (Miltenberger, 2012). Pada sesi ke-2 hingga 16, Y sudah mampu melakukan urutan perilaku yang menjadi target secara mandiri (lihat Tabel 1).

Selain itu, penggunaan prompt sangat berkontribusi terhadap efektivitas dari total-task presentation. Pada program intervensi ini, prompt yang digunakan adalah physical prompt, gestural prompt, dan verbal prompt, lalu dilakukan fading agar anak dibiasakan melakukan secara mandiri hingga tidak lagi membutuhkan bantuan prompt. Meskipun dalam penelitian ini tidak dilakukan manipulasi pemberian prompt, namun secara teoritis (Sabielny \& Cannela-Malone, 2014) mengemukakan bahwa pemberian physical prompt, gestural prompt, dan verbal prompt akan sangat membantu anak dalam memahami urutan perilaku yang diajarkan. Setelah pemberian prompt dan perilaku mulai terbentuk, perlu dilakukan fading dalam pemberian prompt agar anak diberi kesempatan untuk melakukan sendiri perilaku yang diajarkan. Perilaku dapat dinilai berhasil terbentuk ketika anak sudah tidak lagi membutuhkan bantuan prompt.

Jenis dan waktu pemberian reinforcer merupakan faktor berikutnya yang berperan terhadap efektivitas program. Pada progam ini, pelaksana menggunakan dan memberikan reinforcer sesuai dengan perencanaan, yaitu memberikan social reinforcer berupa pujian segera setelah (immediate) subjek berhasil menyelesaikan chain of behaviors sesuai target dan consumable reinforcer setelah $\mathrm{Y}$ menyelesaikan rangkaian perilaku sesuai target (intermitten). Menurut Adibsereshki (2014), halhal tersebut dapat lebih mempertahankan perilaku yang tepat.

Faktor selanjutnya adalah lingkungan yang kondusif untuk proses belajar. Untuk menunjang keberhasilan program, peneliti memodifikasi ruangan, seperti meletakan ember yang sudah berisi air dan gayung di sebelah kloset dan meletakan handuk tangan di tempat yang dapat dijangkau Y. Hal ini mempermudah Y untuk melakukan rangkaian perilaku BAK. Di sisi lain, terdapat faktor lain yang menjadi penghambat perkembangan perilaku $\mathrm{Y}$, yaitu sikap orangtua yang kurang bekerja sama pada sesi awal untuk tetap melatih Y BAK sesuai dengan yang sudah diajarkan oleh peneliti pada saat peneliti tidak ada. Kurangnya sikap kooperatif dari ibu membuat lambatnya 
perkembangan Y pada sesi 1. Meskipun demikian, peneliti selalu memberikan debrief mengenai hasil yang didapat setiap harinya dan menekankan penjelasan dari sisi positif Y. Hal ini membuat ibu memiliki perasaan optimis terhadap kemajuan perkembangan $\mathrm{Y}$ dan ibu berperan lebih aktif untuk melatih Y. Perubahan sikap pada ibu membuat perkembangan $\mathrm{Y}$ menjadi lebih mudah untuk mengalami kemajuan. Menurut Lakhan (2014), konteks lingkungan keluarga dapat berkontribusi terhadap stabilitas pengurangan perilaku yang challenging dan perilaku yang sudah baik pada anak-anak dengan disabilitas intelektual.

Meskipun program intervensi modifikasi perilaku BAK ini dapat dikatakan berhasil, namun tetap memiliki limitasi terkait metode dan teknis pelaksanaannya. Berdasarkan metode pelaksanaannya, penyusun program tidak menyertakan fase generalisasi atau fase mempertahankan perilaku (maintenance) dalam program. Menurut Martin dan Pear (2015), fase tersebut berguna agar perilaku yang diajarkan dapat bertahan dan diaplikasikan di berbagai situasi. Pada peneliti lain disarankan untuk tetap menyertakan fase generalisasi untuk mengajarkan anak melakukan BAK di lingkup yang berbeda-beda, misal di sekolah atau tempat-tempat umum lainnya.

Limitasi lain, terkait teknik pelaksanaan adalah peneliti berperan sebagai pelaksana sekaligus observer pada sesi intervensi. Hal itu membuat pelaksana harus fokus memberikan pengajaran dan memiliki daya ingat yang baik sehingga bisa melakukan pencatatan dengan akurat setelah setiap percobaan. Tidak adanya proses perekaman karena orangtua tidak memberi izin untuk merekam gambar dan suara, membuat setiap sesi percobaan tidak dapat ditinjau ulang untuk meminimalisir kemungkinan adanya kesalahan dalam pencatatan.

Perbedaan penelitian ini dengan penelitian sebelumnya terletak pada penggunaan teknik total-task presentation yang mengajarkan satu per satu rangkaian perilaku BAK secara berurutan. Berbeda dengan penelitian sebelumnya yang lebih banyak menerapkan RTT untuk meningkatkan keterampilan BAK pada anak dengan disabilitas intelektual. Peningkatan yang terjadi pada partisipan membutuhkan waktu selama 14 hari. Waktu tersebut relatif lebih singkat jika dibandingkan dengan metode RTT yang membutuhkan waktu selama 1-10 bulan hingga anak dapat BAK secara mandiri (penelitian RTT dalam Kroeger \& Sorensen-Burnworth, 2009). Positifnya, metode RTT dinilai sebagai program yang memberikan pengajaran secara mendetail. Tidak hanya berfokus pada perilaku BAK, namun juga mengajarkan anak untuk terbiasa duduk di kloset, melepas dan memakai celana, dan juga membentuk anak agar berinisiatif pergi ke toilet ketika ingin BAK.

Berkaitan dengan penerapan program modifikasi perilaku, secara teori tidak ada batasan atau ketentuan yang pasti terkait waktu pelaksanaan. Dalam buku manual disebutkan bahwa semakin banyak percobaan yang diberikan kepada anak dalam setiap sesinya, maka akan semakin cepat perilaku untuk terbentuk (Martin \& Pear, 2015). Hanya saja, banyaknya percobaan yang diberikan pada anak tidak boleh menimbulkan kerugian pada anak, ada unsur pemaksaan, kekerasan, dan tidak memperhatikan kesejahteraan anak.

Hasil dari penelitian ini menunjukan adanya efektivitas penerapan total-task presentation dalam membentuk perilaku BAK pada anak dengan disabilitas intelektual moderat meskipun menggunakan metode single subject. Hasil dari penelitian yang menggunakan single subject tetap dapat diaplikasikan kepada subjek lain, namun terbatas hanya pada subjek yang memiliki karakteristik sejenis (Horner dkk., 2007). Metode intervensi pada penelitian hanya dapat diterapkan pada partisipan lain yang sama-sama memiliki kondisi disabilitas intelektual pada level moderat dan berjenis kelamin laki-laki. Hal tersebut menjadi bagian 
dari keterbatasan metode single subject, namun bukan berarti tidak dapat diaplikasikan pada subjek lainnya. Di sisi lain, penelitian yang menggunakan metode single subject sangat menyesuaikan kondisi serta respon yang diberikan oleh partisipan, sehingga perubahan perilaku partisipan dapat terlihat lebih detail dan jelas (Gravetter \& Forzano, 2012).

Hal yang menjadi fokus lainnya mengenai keterbatasan penelitian ini adanya pemberian reinforcement berupa makanan yang kurang sehat. Pada anak dengan disabilitas intelektual moderat tidak ada pantangan terhadap jenis atau kandungan makanan tertentu (Nyaradi, Li, Hickling, Foster, \& Oddy, 2013). Hanya saja, jika diberikan secara berlebihan maka dapat berdampak pada kesehatan anak, terutama kesehatan gigi. Pada penelitian ini, pemberian makanan tersebut tetap dikontrol jumlah pemberiannya untuk mengantisipasi hal tersebut. Jika diberikan dalam kadar yang tidak berlebihan, maka dampak terhadap kesehatannya dapat diminimalisir. Meskipun demikian, sangat disarankan pada penelitian selanjutnya untuk tetap memberikan makanan sehat yang disukai anak.

\section{SIMPULAN}

Berdasarkan data-data, diperoleh kesimpulan bahwa program modifikasi perilaku BAK dengan menggunakan teknik total-task presentation dan most-to-least prompt efektif untuk meningkatkan kemampuan BAK pada anak usia 10 tahun 2 bulan dengan disabilitas intelektual moderat. Teknik-teknik tersebut dapat digunakan untuk pengajaran perilaku BAK dengan membutuhkan waktu sekitar 14 hari dengan 81 kali percobaan. Setelah diberikan program ini, subjek berhasil menguasai seluruh rangkaian perilaku BAK (22 chain of behaviors) secara mandiri dari yang sebelumnya hanya menguasai sembilan chain of behaviors secara mandiri.

\section{DAFTAR PUSTAKA}

Adibsereshki, N., Abkenar, S. J., Ashoori, M., \& Mirzamani, M. (2014). The effectiveness of using reinforcements in the classroom on the academic achievement of students with intellectual disabilities. Journal of Intellectual Disabilities, 19(1), 83-93.

American Psychiatric Association. (2013). Diagnostic and statistical manual of mental disorders (5th ed.). Washington, DC: Author.

Behrani, P., \& Deka, D. B. (2016). Concerns for individuals with intellectual disability in India. In Gopalan, R. T. (Ed.), Handbook of Research on Diagnosing, Treating, and Managing Intellectual Disabilities, (pp.204-219). USA: IGI Global.

Collins, B. C. (2012). Systematic instruction for student with moderate and severe disabilities. USA: Brookes Publishing.

Deshmukh, D. V. (2016). Strategies used to modify the behaviors of children with intellectual disability. Indian Journal of Health and Wellbeing, 7(7), 753-756.

Doan, D., \& Toussaint, K. A. (2016). A parentoriented approach to rapid toilet training. International Electronic Journal of Elementary Education, 9(2), 473-486.

Emerson, E., Hatton, C., Dickson, K., Caine, A., \& Bromley, J. (2012). Clinical psychology and people with intellectual disabilities (2nd ed.). UK: Willey Blackwell.

Greer, B. D. (2013). An evaluation of toilet training procedures (Doctoral disertation). University of Kansas, USA. Retrieved from https://kuscholarworks.ku.edu/bitstream/h 
andle/1808/12227/Greer_ku_0099D_1296 1_DATA_1.pdf; sequence $=1$

Gravetter, F. J., \& Forzano, L. A. N. (2012). Research methods for the behavioral sciences (4th ed.). Canada: Wadsworth Cengage Learning.

Horner, R. H., Carr, E. G., Halle, J., McGee, G., Odom, S., \& Wolery, M. (2007). The use of single-subject research to identify evidence-based practice in special education. Council for Exceptional Children, 71(2), 165-179.

Jameson, J. M., Walker, R., Utley, K., \& Maughan, R. (2012). A comparison of embedded total task instruction in teaching behavioral chains to massed oneon-one instruction for students with intellectual disabilities. Behavior Modification, 36(3), 320-340.

Kazdin, A. E. (2013). Behavior modification in applied settings (7th ed.). Illinois: Waveland Press.

Kroeger, K. A., \& Sorensen-Burnworth, R. (2009). Toilet training individuals with autism and other developmental disabilities: A critical review. Research in Autism Spectrum Disorders, 3, 607-618.

Kusharyani, F., \& Kurnianigrum W. (2017). Penerapan total-task presentation dalam meningkatkan kemampuan menggosok gigi pada anak moderate intellectual disability. Jurnal Muara Ilmu Sosial, Humaniora, dan Seni, 1(2), 32-40.

Lakhan, R. (2014). Behavioral management in children with intellectual disabilities in a resource-poor setting in barwani, India. Indian Journal of Psychiatry, 56(1), 39.
Levato, L. E., Aponte, C. A., Wilkins, J., Travis, R., Aiello, R., Zanibbi, K., Loring, W. A., Butter, E., Smith, T., \& Mruzek, D. W. (2016). Use of urine alarms in toilet training children with intellectual and develeopmental disabilities: A review. Research in Developmental Disabilities, 53-54, 232-241.

Marotz, L. R., \& Ellen K. E. (2013). Developmental profiles: Pre birth through adolescence (7th ed.). USA: Wadsworth.

Martin, G., \& Pear, J. (2015). Behaviour modification: What it is and how to do it (10th Ed.). USA: Pearson Education.

Miltenberger, R. G. (2012). Behavior modification: Principles And Procedures (5th ed.). USA: Wadsworth.

Murpratiwi, I. A., \& Tjakrawilaksana, M. A. (2018). Prompting dan positive reinforcement untuk meningkatkan keterampilan berpakaian pada anak dengan intellectual disability. Jurnal Psikologi Teori dan Terapan, 8(2), 112123.

Nelson, R., \& Israel, A. C. (2015). Abnormal child and adolescent psychology with $D S M-V$ updates (8th ed.). New York: Pearson.

Nyaradi, A., Li, J., Hickling, S., Foster, J., \& Oddy, W. H. (2013). The role of nutrition in children's neurocognitive development, from pregnancy through childhood: Review article. Frontiers in Human Neuroscience, 7. doi:10.3389/fnhum.2013.00097

Obi, O., Braun, K. V. N., Baio, J., DrewsBotsch, C., Devine, O., \& Yearginallsopp, M. (2011). Effect of incorporating adaptive functioning scores on the prevalence if intellectual disability. American Journal on Intellectual and 
Developmental Disabilities, 116(5), 360- Sabielny, L. M., \& Cannella-Malone, H. I. 70.

Rinald, K., \& Mirenda, P. (2012). Effectiveness of a modified rapid toilet training workshop for parents of children with developmental disabilities. Research in Developmental Disabilities, 33(3) 933943. (2014). Comparison of prompting strategies on the acquisition of daily living skills. Education and Training in Autism and Developmental Disabilities, 49(1), 145-152.

Wantah, M. J. (2007). Pengembangan kemandirian anak tunagrahita mampu latih. Jakarta: Depdiknas. 